\title{
RAPID AND SIMPLE DETERMINATION OF IBUPROFEN AND CAFFEINE IN FIXED-DOSE COMBINATION FORMULATIONS: APPLICATION TO DISSOLUTION STUDIES
}

\section{JOSE RAUL MEDINA-LOPEZ*, JOAQUIN ALEXANDRO SOTO-JUHA, JUAN MANUEL CONTRERAS-JIMÉNEZ}

\author{
Departamento Sistemas Biologicos, Universidad Autonoma Metropolitana Xochimilco, Mexico City, Mexico
}

Email: rmlopez@correo.xoc.uam.mx

Received: 02 Feb 2021, Revised and Accepted: 20 Mar 2021

\section{ABSTRACT}

Objective: To develop a UV-derivative spectrophotometric method with zero-crossing determinations for the simultaneous quantification of ibuprofen (IBU) and caffeine (CAF) in fixed-dose combination formulations (soft gelatin capsules). The proposed method was validated, and it was applied to determine the in vitro dissolution performance of IBU and CAF from a commercial formulation.

Methods: The method is based on the use of the second-derivatives of the zero-order spectra and measurement at zero-crossing wavelengths. Linearity, accuracy, precision, stability, and influence of the filter were evaluated. Dissolution profiles of IBU and CAF were obtained with the USP Apparatus 2 at $100 \mathrm{rpm}$ and $900 \mathrm{ml}$ of $0.1 \mathrm{M}$ phosphate buffer $\mathrm{pH} 7.4$ as dissolution medium. Dissolution samples were treated with the proposed UV-derivative method and results were compared with data previously published.

Results: The zero-crossing points for the determination of IBU and CAF were found at $235.6 \mathrm{~nm}$ and $218.8 \mathrm{~nm}$, respectively. The method was linear in the range of $7.5-15 \mu \mathrm{g} / \mathrm{ml}$ for IBU and $5-25 \mu \mathrm{g} / \mathrm{ml}$ for CAF $\left(\mathrm{R}^{2}>0.999,{ }^{*} \mathrm{P}<0.05\right)$. The precision and accuracy of the method were within acceptable criteria $(\mathrm{CV}<0.99 \%$ and recovery $97.97 \%$ for IBU and $\mathrm{CV}<1.76 \%$ and recovery $99.05 \%$ for CAF). Fiberglass filters were the best option to filter samples and stability of all drugs was adequate when solutions were stored at $25^{\circ} \mathrm{C}$ during $24 \mathrm{~h}$. Dissolution of IBU and CAF at 60 min was $99-100 \%$ with dissolution profiles of sigmoidal S-shape. Weibull function and Logistic were the best-fit models that describe the in vitro dissolution performance of both drugs.

Conclusion: The proposed UV-derivative method allows the simultaneous determination of IBU and CAF in fixed-dose combination formulations. The method generates reliable information that can be compared with published data. The proposed UV-derivative method is rapid and simple and can be easily adopted for routine analysis of IBU and CAF.

Keywords: Caffeine, Derivative spectroscopy, Ibuprofen, USP Apparatus 2

(C) 2021 The Authors. Published by Innovare Academic Sciences Pvt Ltd. This is an open access article under the CC BY license (https://creativecommons.org/licenses/by/4.0/) DOI: https://dx.doi.org/10.22159/ijap.2021v13i3.40975. Journal homepage: https://innovareacademics.in/journals/index.php/ijap

Many drug products containing mixtures of drugs are manufactured as fixed-dose combination formulations. Some advantages have been identified for this kind of formulations: 1 . Greater efficacy compared with higher dose monotherapy; 2 . Reduced risk of adverse reactions relative to higher dose monotherapy; 3 . Lower overall costs, and 4 . Improve medication concordance [1]. These advantages can be seen when treating different conditions with various combinations of drugs. Fixed-dose combination formulations of ibuprofen (IBU) and caffeine (CAF) are widely available as over-the-counter products. IBU is a non-steroidal anti-inflammatory drug (NSAID) with analgesic, anti-inflammatory, and antipyretic properties [2]. Some authors have studied the effect of CAF on pain management [3-5] $\mathrm{CAF}$ is an extremely common drug in commercial products, and it occurs in a wide range of cold remedies, analgesics and other types of medicines. CAF is clinically safe, and it has good $\mathrm{pH}$-independent aqueous solubility in the physiological $\mathrm{pH}$ range $(\sim 50 \mathrm{mg} / \mathrm{ml})[6]$. Chemical structures of IBU and CAF are shown in fig. 1.<smiles>CC(C)Cc1ccc(C(C)C(=O)O)cc1</smiles><smiles>Cn1c(=O)c2c(ncn2C)n(C)c1=O</smiles>

Fig. 1: Chemical structures of ibuprofen (left) and caffeine (right)

A review of analgesic effect of IBU and CAF mixture was previously reported [7]. The use of this combination in preclinical studies $[8,9]$, the effectiveness of a single dose of IBU/CAF tablets in postoperative pain [10] and especially in molar surgeries has been widely documented [10-14].

According to Biopharmaceutics Classification System (BCS) criteria drugs with low solubility and high permeability are classified as class II drugs [15]. Several authors have classified IBU as a class II drug $[16,17]$. By the available scientific information, formulations with IBU as the only active pharmaceutical ingredient (API), are candidates to waiver in vivo studies. A biowaiver monograph for immediate-release solid oral dosage forms containing IBU has been published [2]. However, only fixed-dose combinations containing BCS class I, or class III, or a combination of class I and class III may be candidates for a biowaiver [18] so this approach for IBU/CAF drug products, is not applicable. Official dissolution test for IBU suspensions and tablets are described in the United States Pharmacopeia (USP) [19]. Both methods use the USP Apparatus 2 at $50 \mathrm{rpm}$ and $900 \mathrm{ml}$ of phosphate buffer $\mathrm{pH} 7.2$ as dissolution medium. To date, no official dissolution test for IBU/CAF fixed-dose combination formulations is available [19].

Several authors have studied the simultaneous determination of CAF combined with some NSAIDs in pharmaceutical formulations [20, 21]. The quantification of the ternary mixture of acetaminophen (ACE), IBU, and CAF in solid dosage forms using analytical methods as UV and HPLC [22, 23] as well as voltammetric determination [24] have been previously described. Specifically, for IBU/CAF mixture, analytical methods with gas chromatography in pharmaceutical dosage forms [25], Raman spectroscopy in water samples [26] and fluorescence in urine samples [27] were recently reported. However, in a complete review of spectrophotometric methods for determination of some mixtures the combination of IBU and CAF is not included [28].

In the present study, a rapid and simple UV-derivative method with measurements at zero-crossing points is proposed for determination of IBU and CAF in fixed-dose combination formulations (soft gelatin 
capsules). The method was applied in dissolution studies using USP Apparatus 2 (paddle) at $100 \mathrm{rpm}$ and $0.1 \mathrm{M}$ phosphate buffer $\mathrm{pH} 7.4$ as dissolution medium. The objective is to have a reliable and easy method to determine IBU and CAF using the minimum possible analytical resources. Results were compared with published data.

IBU and CAF standards were purchased from Sigma-Aldrich Co. (St. Louis MO, USA). Sodium phosphate monobasic and dibasic crystals and methanol HPLC grade were purchased from J. T. Baker-Mexico (Xalostoc, Mexico). The fixed-dose combination formulation of IBU and CAF (200/65-mg, respectively) used was Advil Lift ${ }^{\circledR}$ capsules (Procaps S. A., Barranquilla Colombia).

For UV derivative analysis, a double beam UV/Vis spectrophotometer (Perkin Elmer Lambda 35, Waltham MA, USA) with $1-\mathrm{cm}$ quartz cells was used. The operating conditions were second-derivative $\left({ }^{2} \mathrm{D}\right)$ mode with scan speed of $240 \mathrm{~nm} / \mathrm{min}$, slit width $2.0 \mathrm{~nm}$ and sampling interval $1.0 \mathrm{~nm}$.

The preparation of standard solutions of IBU and CAF were as follows: $10 \mathrm{mg}$ of each drug were separately added to $10 \mathrm{ml}$ volumetric flasks. A volume of $5 \mathrm{ml}$ of methanol was added to each one then, flasks were sonicated during $10 \mathrm{~min}$. Later, both flasks were diluted to the mark with $0.1 \mathrm{M}$ phosphate buffer $\mathrm{pH}$ 7.4. From both stock solutions, five solutions of IBU $(7.5-15 \mu \mathrm{g} / \mathrm{ml})$ and five solutions of CAF (5-25 $\mu \mathrm{g} / \mathrm{ml})$ in $0.1 \mathrm{M}$ phosphate buffer $\mathrm{pH} 7.4$ were prepared. Then, zero-order spectra of all solutions from 200 to $350 \mathrm{~nm}$, using $1-\mathrm{cm}$ quartz cells, were recorded and stored. To quantify IBU and CAF, the stored spectra of the standard calibration curves were used to calculate the ${ }^{2} \mathrm{D}$. To quantify IBU and CAF in dissolution samples, the zero-order spectra of filtered solutions at adequate concentrations were recorded and stored. Subsequently, the ${ }^{2} \mathrm{D}$ spectra of IBU and CAF, as well as data of standard calibration curves, were used to calculate the percent dissolved of each drug at previously established sampling times.

To test linearity, two standard calibration curves of IBU and CAF were plotted. Data were fitted by linear regression analysis and the correlation coefficients and regression analysis of variance (ANOVA) were calculated. The $95 \%$ Confidence Interval $\left(\mathrm{CI}_{95 \%}\right.$ ) for the intercept of each mean standard calibration curve was calculated. Precision was demonstrated with the calculation of percent of coefficient of variation $(\% \mathrm{CV}):[($ standard deviation/mean) $\times 100]$ of response factor. Response factor represents the proportionality of response $v s$. drug concentration. A CV $\leq 2 \%$ was considered as a good criterion. Accuracy and precision were evaluated with the preparation of three synthetic mixtures of IBU and CAF with concentrations within standard calibration curves range of each drug. Then, four samples of each solution and a standard calibration curve of each drug were analyzed with the proposed UV-derivative method. Accuracy was validated by recovery data and precision with the calculation of \%CV. Added $v s$. recovered concentrations were plotted and linear regression analysis were calculated. The $\mathrm{CI}_{95 \%}$ of slopes and intercepts, as well as $\% \mathrm{CV}$ at each concentration level, were estimated. Drug retention by some kinds of filters was evaluated by response of IBU and CAF before and after a synthetic mixture of both drugs was filtered $(10 \mu \mathrm{g} / \mathrm{ml}$ of IBU and $20 \mu \mathrm{g} / \mathrm{ml}$ of CAF). Nitrocellulose and fiberglass filters were tested. Percent of absolute difference (\%AD): [((initial response-final response)/initial response) $\times 100$ ] was calculated with 10 samples. The IBU and CAF stability was evaluated by stored a synthetic mixture $\left(13 \mu \mathrm{g} / \mathrm{ml}\right.$ of IBU and $20 \mu \mathrm{g} / \mathrm{ml}$ of CAF) at 4 and $25^{\circ} \mathrm{C}$ during 24 and $72 \mathrm{~h}$. The \%AD was calculated by triplicate at each temperature and sampling time.

Dissolution profiles of IBU/CAF capsules were obtained with a USP Apparatus 2 (paddle) (Sotax AT-7 Smart, Switzerland) at $100 \mathrm{rpm}$ and $900 \mathrm{ml}$ of $0.1 \mathrm{M}$ phosphate buffer $\mathrm{pH} 7.4\left(37.0 \pm 0.5{ }^{\circ} \mathrm{C}\right)$. Each dissolution profile was calculated with 12 replicates. After addition of capsules, $5 \mathrm{ml}$ of filtered dissolution sample was withdrawn at 10 , $25,30,45$, and $60 \mathrm{~min}$. All samples were diluted at adequate concentrations and they were analyzed by the proposed UVderivative method. Dissolved drug at 60 min $\left(Q_{60}\right)$ was used for comparative purposes. In order to describe the in vitro dissolution performance of IBU/CAF from commercial capsules mean dissolution time (MDT) and dissolution efficiency (DE) were calculated. Both model-independent parameters have been suggested as suitable parameters to compare dissolution profiles $[29,30]$ and to establish an in vitro/in vivo correlation [31]. Additionally, dissolution data of both drugs were fitted by several mathematical models commonly used in dissolution studies as Weibull, logistic, Gompertz and Probit. Equations are shown in table 1. Best-fit model was the one that presented highest $\mathrm{R}^{2}$ adjusted and lowest Akaike Information Criterion (AIC) [32]. DDSolver add-in program was used to calculate MDT and DE and fit dissolution data [33].

Table 1: Mathematical models used to fit dissolution data of IBU and CAF

\begin{tabular}{lc}
\hline Model & Equation \\
\hline Weibull & $F=F_{\max } \cdot\left(1-e^{-\frac{t^{\beta}}{\alpha}}\right)$ \\
Logistic & $F=F_{\max } \cdot \frac{e^{\alpha+\beta \cdot \log (t)}}{1+e^{\alpha+\beta \cdot \log (t)}}$ \\
& $F=F_{\max } \cdot e^{-\beta \cdot e^{-k \cdot t}}$ \\
Gompertz & $F=100 \cdot \phi[\alpha+\beta \cdot \log (t)]$ \\
\hline
\end{tabular}

IBU: ibuprofen. CAF: caffeine

The zero-order spectra of $0.1 \mathrm{M}$ phosphate buffer $\mathrm{pH} 7.4$ solutions of IBU at $10 \mu \mathrm{g} / \mathrm{ml}, \mathrm{CAF}$ at $15 \mu \mathrm{g} / \mathrm{ml}$ and a synthetic mixture of both drugs (MIX) at same concentrations are depicted in fig. 2A. The zero-order spectrum of MIX solution demonstrated a marked overlapping so that the direct and simultaneous determination of IBU and CAF was not possible. The ${ }^{2} \mathrm{D}$ of zero-order spectra of five standard solutions of IBU $(7.5-15 \mu \mathrm{g} / \mathrm{ml})$ and five solutions of CAF $(5-25 \mu \mathrm{g} / \mathrm{ml})$, as well as MIX solution $(10 \mu \mathrm{g} / \mathrm{ml}$ of IBU and $15 \mu \mathrm{g} / \mathrm{ml}$ of CAF), are shown in fig. 2B. The zero-crossing points for determination of IBU and CAF were identified at 235.6 and $218.8 \mathrm{~nm}$, respectively. At these wavelengths, all analytical signals were proportional to the concentrations of drugs and as can be seen, no interference of each drug was found.
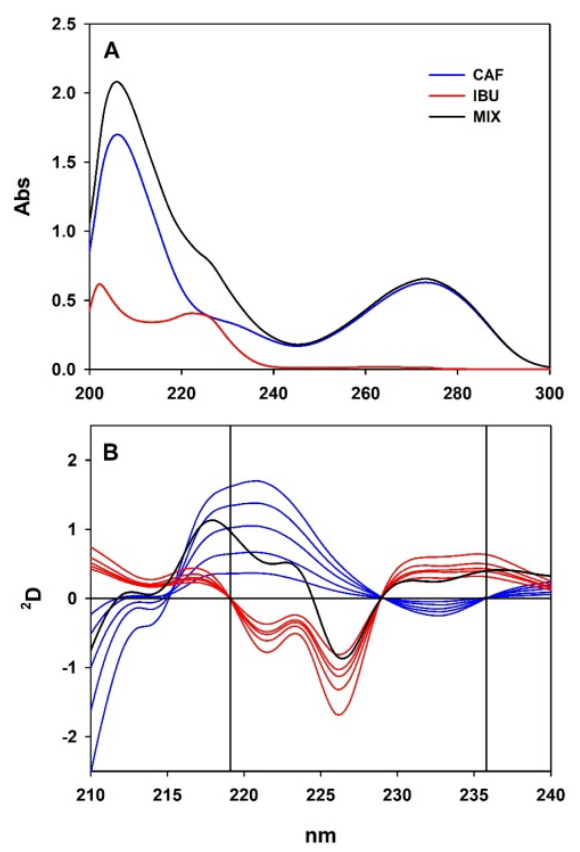

Fig. 2: (A) Zero-order spectra of a solution of ibuprofen (IBU) at $10 \mu \mathrm{g} / \mathrm{ml}$, caffeine (CAF) at $15 \mu \mathrm{g} / \mathrm{ml}$ and a synthetic mixture of both drugs (MIX) at same concentrations. (B) Second-derivative ( $\left.{ }^{2} D\right)$ of standard calibration curves and MIX solution. Vertical lines show the zero-crossing points used to quantify IBU (235.6 $\mathrm{nm})$ and CAF (218.8 $\mathrm{nm})$

Of each drug, two standard solutions were prepared, and mean linear regression equations were as follows: $y=0.0502 x-0.0154$ for IBU and $y=0.0797 x+0.0138$ for CAF. All standard calibration curves were significant $\left(\mathrm{R}^{2}>0.999,{ }^{*} \mathrm{P}<0.05\right)$. Plots are shown in fig. 3A and fig. 3B. The 
$\mathrm{CI}_{95 \%}$ calculated for intercept was- 0.044 to 0.013 for IBU and- 0.014 to 0.041 for CAF. The $\%$ CV of response factor was $1.75 \%$ for IBU and $1.86 \%$ for $\mathrm{CAF}$. The linear regression equations calculated to test accuracy were as follows: $\mathrm{y}=1.0291 \mathrm{x}-0.5758$ for IBU and $\mathrm{y}=1.053 \mathrm{x}-0.7383$ for CAF. All linear regressions were significant $\left(\mathrm{R}^{2}>0.99,{ }^{*} \mathrm{P}<0.05\right)$. Plots are shown in fig. 3C and fig. 3D. The $\mathrm{Cl}_{95 \%}$ for slopes and intercepts, respectively, were as follows: 0.56 to 1.49 and -6.10 to 4.95 for IBU and 0.66 to 1.44 and -5.91 to 4.43 for CAF. The $\% \mathrm{CV}$ of recovery data were 0.58 to $0.99 \%$ for IBU and 0.34 to $1.76 \%$ for CAF. Results shown a good accuracy and precision of the proposed UV-derivative method.
IBU
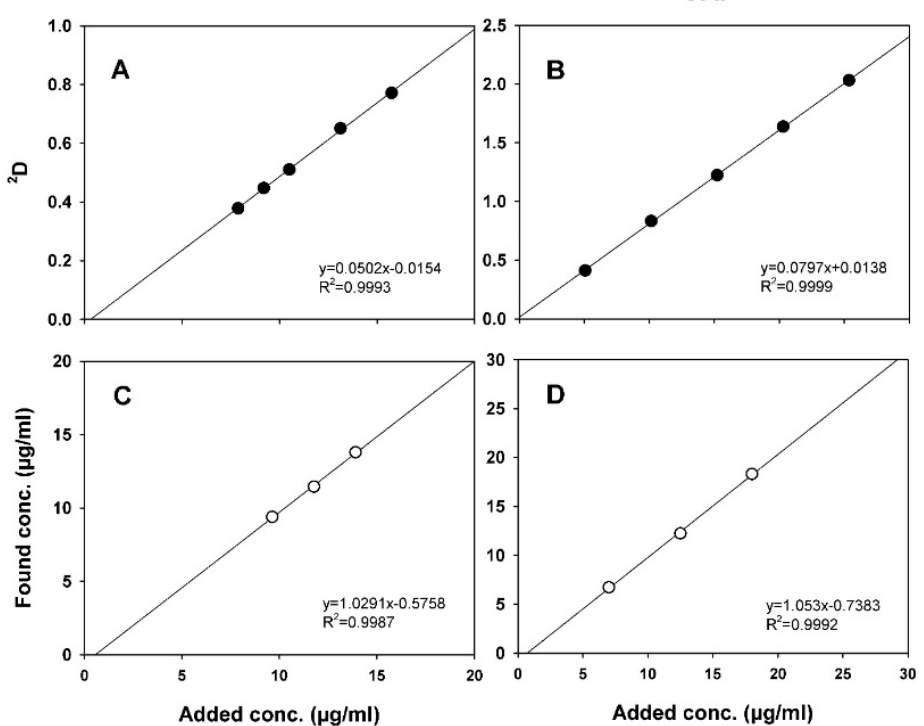

Fig. 3: (A) and (B) Standard calibration curves (mean values, $n=2$ ). (C) and (D) Synthetic mixtures (mean values, $n=4)$ of ibuprofen (IBU) and caffeine (CAF). All linear regressions were significant $(* P<0.05)$

The lowest values of \%AD to test the influence of the filter were $0.46 \%$ for IBU and $4.6 \%$ for CAF, both data were calculated with fiberglass filters so, this kind of filter was used in dissolution studies. Values of \%AD to test the stability of IBU at $25{ }^{\circ} \mathrm{C}$ and 24 and $72 \mathrm{~h}$ were-3.25 and $-4.74 \%$, respectively. Data of CAF at same conditions were 0.40 and $0.88 \%$. Values of \%AD of IBU at $4{ }^{\circ} \mathrm{C}$ and at 24 and 72 $\mathrm{h}$ were- 5.03 and $-7.05 \%$, respectively. Data of CAF at same conditions were- 0.6 and $-0.63 \%$. Results suggest better stability of a synthetic mixture of IBU and CAF at $25^{\circ} \mathrm{C}$ for $24 \mathrm{~h}$.

Dissolution profiles of IBU and CAF from fixed-dose combination formulation are depicted in fig. 4. The $\mathrm{Q}_{60}$, MDT, and DE values are shown in table 2 .

The in vitro dissolution performance of IBU and CAF shown a sigmoidal S-shape with a complete drug release at $60 \mathrm{~min}(100 \%)$. Application of the UV-derivative method showed that excipients do not affect the accuracy of our results since recovery (expressed as $\mathrm{Q}_{60}$ data) is similar than results obtained with gas chromatography and HPLC methods applied at IBU/CAF fixed-dose combination formulations (99-100\% for both drugs) [25]

The $\mathrm{R}^{2}$ adjusted and AIC values as a result of adjusting IBU and CAF dissolution data by several mathematical models are shown in table 3. Weibull function was the best-fit model for IBU data and the Logistic equation for CAF data.

Weibull and Logistic models cannot describe drug release kinetics, but they can describe the curve in terms of applicable parameters [34]. The shape parameter $\beta$ characterizes the dissolution profile as exponential $(\beta=1)$; as sigmoid S-shaped, with upward curvature followed by a turning point $(\beta>1)$; or as parabolic, with a steeper initial slope that is consistent with the exponential $(\beta<1)$ [35]. In the present study, mean $\beta$ values \pm standard deviation of IBU (Weibull) and CAF (Logistic) were $2.79 \pm 0.37$ and $10.08 \pm 1.93$, respectively, and since $\beta$ values were $>1$ sigmoidal profile for both drugs was considered. Similar results have been reported by several authors wherein a dissolution study of IBU suspensions (USP Apparatus 2 and 4 and phosphate buffer $\mathrm{pH}$ 7.2) two formulations were well fitted by Weibull function $\left(\mathrm{R}^{2}\right.$ adjusted $\left.>0.99\right)$ [36]. Another dissolution study but with
ACE/IBU fixed-dose combination formulations (USP Apparatus 2 and 4 and $0.1 \mathrm{M}$ phosphate buffer $\mathrm{pH}$ 7.4) reported a best-fit with Weibull distribution $\left(\mathrm{R}^{2}\right.$ adjusted $\left.>0.999\right)$ for both drugs [37]. The fit of dissolution data to the Weibull function and Logistic model emphasized the Sshape or sigmoidal dissolution profiles [34].
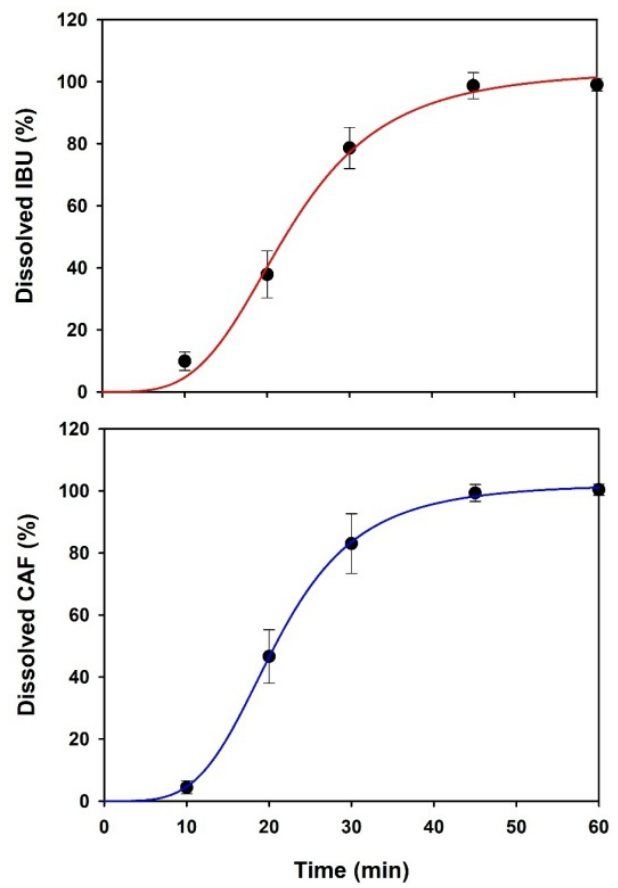

Fig. 4: Dissolution profiles of ibuprofen (IBU) and caffeine (CAF) obtained with USP Apparatus 2 at $100 \mathrm{rpm}$ and $900 \mathrm{ml}$ of $0.1 \mathrm{M}$ phosphate buffer pH 7.4 as dissolution medium. Mean value \pm standard deviation, $\mathrm{n}=12$ 
Table 2: Model-independent parameters of IBU and CAF

\begin{tabular}{llll}
\hline Drug & $\mathbf{Q}_{60}(\mathbf{\%})$ & MDT (min) & DE (\%) \\
\hline IBU & $99.05 \pm 0.58$ & $22.81 \pm 0.52$ & $61.39 \pm 0.89$ \\
CAF & $100.37 \pm 0.72$ & $22.23 \pm 0.72$ & $63.17 \pm 1.15$ \\
\hline
\end{tabular}

Mean value \pm standard error medium, $n=12$. IBU: ibuprofen. CAF: caffeine. $\mathrm{Q}_{60}$ : dissolved drug at 30 min. MDT: mean dissolution time. DE: dissolution efficiency

Table 3: Criteria used to find the best-fit model of IBU and CAF dissolution data

\begin{tabular}{llll}
\hline Drug & Weibull & Logistic & Gompertz \\
\hline $\mathrm{R}^{2}$ adjusted & & & Probit \\
IBU & 0.9912 & 0.9819 & 0.9838 \\
CAF & 0.9937 & 0.9964 & 0.9963 \\
AIC & & & 0.9826 \\
IBU & 21.65 & 25.10 & 24.44 \\
CAF & 20.11 & 14.88 & 13.33 \\
\hline
\end{tabular}

Mean value \pm standard error medium, $n=12$. IBU: ibuprofen. CAF: caffeine

On the other hand, the in vitro dissolution performance of CAF from fixed-dose formulations has been previously reported. ACE/CAF tablets were tested with USP Apparatus 1 at $100 \mathrm{rpm}$ and $900 \mathrm{ml}$ of fat-rich media as dissolution medium. Under these conditions more than $80 \%$ of dissolved CAF at 20 min was found [6]. CAF in a ternary mixture of drugs (tablets) was dissolved with USP Apparatus 1 at $100 \mathrm{rpm}$ and $900 \mathrm{ml}$ of $0.1 \mathrm{~N} \mathrm{HCl}$. More than $80 \%$ of dissolved CAF at $20 \mathrm{~min}$ was found [38]. In our in vitro dissolution study, more than $80 \%$ of dissolved CAF was found but at $30 \mathrm{~min}(82.99 \pm 9.63 \%$, mean value \pm standard deviation). As the dissolution profile of CAF shown a sigmoidal S-shape it is not possible to find $80 \%$ of dissolved drug at $20 \mathrm{~min}$ but $10 \mathrm{~min}$ latter this dissolution extent was achieved. Additionally, CAF as only API manufactured in three different hypromellose (HPMC)-based controlled release tablets were tested with USP Apparatus 3 (10 and $15 \mathrm{dpm}$ ), water and biorelevant media (fed and fasted) [39]. Dissolution data were well fitted by the Weibull function $\left(\mathrm{R}^{2}>0.98\right)$ and under certain conditions shape parameter $b$ was $>1$. In that study no other mathematical model to fit dissolution data was considered however and as previously stated, Weibull distribution emphasized the S-shape or sigmoidal dissolution profiles.

The proposed UV-derivative method was an analytical procedure successfully used to simultaneously identify IBU and CAF in fixeddose combination formulations. This kind of methods avoid the use of toxic solvents such as those used by HPLC methods and expensive laboratory equipment requiring specialized maintenance. The proposed method is an analytical procedure that not needing any additional mathematical calculations and can be easily adopted for routine analysis of IBU/CAF soft gelatin capsules.

\section{FUNDING}

Nil

\section{AUTHORS CONTRIBUTIONS}

All authors have contributed equally.

\section{CONFLIC OF INTERESTS}

\section{Declared none}

\section{REFERENCES}

1. Bell DSH. Combine and conquer advantages and disadvantages of fixed-dose combination therapy. Diabetes Obes Metab 2013;15:291-300.

2. Potthast H, Dressman JB, Junginger HE, Midha KK, Oeser $H$, Shah $\mathrm{VP}$, et al. Biowaiver monographs for immediate-release solid oral dosage forms: ibuprofen. J Pharm Sci 2005;94:2121-31.

3. Tavares C, Sakata RK. Caffeine in the treatment of pain. Rev Bras Anestesiol 2012;62:387-401.

4. Grama P, Oltea MP, Zah CA. Effect of caffeine in pain management. Acta Marisiensis Seria Med 2020;66:127-31.
5. Shah KM, Dadhaniya P, Trivedi VT. Effect of caffeine in an experimental model of rheumatoid arthritis in rats. Int J Pharm Pharm Sci 2015;7:364-7.

6. Williams HD, Barrett DA, Ward R, Hardy IJ, Melia CD. A liquid chromatography method for quantifying caffeine dissolution from pharmaceutical formulations into colloidal, fat-rich media. J Chromatogr B: Anal Technol Biomed Life Sci 2010;878:1739-45.

7. Polski A, Kasperek R, Sobotka Polska K, Poleszak E. Review on analgesic effect of co-administrated ibuprofen and caffeine. Curr Issues Pharm Med Sci 2014;27:10-3.

8. Medina JR, Dominguez Ramirez AM, Jung H, Bravo G, Diaz Reval MI, Deciga Campos M, Lopez Muñoz FJ. Enhancement of antinociception by co-administration of ibuprofen and caffeine in arthritic rats. Eur J Pharmacol 2006;544:31-8.

9. Medina R, Hurtado M, Soria Arteche O, Moreno Rocha LA, Jung H, Lopez Munoz FJ. PK/PD of rac-ibuprofen co-administered with caffeine: a preclinical study using PIFIR model. Latt Am J Pharm 2018;37:1638-45.

10. Bergese $\mathrm{S}$, Castellon Larios K. The effectiveness of a single dose of oral ibuprofen plus caffeine in acute postoperative pain in adults. Br Med J Evid Based Med 2016;21:24.

11. Forbes JA, Beaver WT, Jones KF, Kehm CJ, Smith WK, Gongloff CM, et al. Effect of caffeine on ibuprofen analgesia in postoperative oral surgery pain. Clin Pharmacol Ther 1991;49:674-84.

12. McQuay HJ, Angell K, Carroll D, Moore RA, Juniper RP. Ibuprofen compared with ibuprofen plus caffeine after third molar surgery. Pain 1996;66:247-51.

13. Weiser T, Richter E, Hegewisch A, Muse DD, Lange R. Efficacy and safety of a fixed-dose combination of ibuprofen and caffeine in the management of moderate to severe dental pain after third molar extraction. Eur J Pain 2018;22:28-38.

14. Forderreuther $S$, Lampert A, Hitier S, Lange R, Weiser T. The impact of baseline pain intensity on the analgesic efficacy of ibuprofen/caffeine in patients with acute postoperative dental pain: post hoc subgroup analysis of a randomized controlled trial. Adv Ther 2020;37:2976-87.

15. Amidon GL, Lennernas H, Shah VP, Crison JRA. Theoretical basis for a biopharmaceutic drug classification: the correlation of in vitro drug product dissolution and in vivo bioavailability. Pharm Res 1995;12:413-20.

16. Lindenberg M, Kopp S, Dressman JB. Classification of orally administered drugs on the World Health Organization model list of essential medicines according to the biopharmaceutics classification system. Eur J Pharm Biopharm 2004;58:265-78.

17. Kasim NA, Whitehouse M, Ramachandran C, Bermejo M, Lennernäs H, Hussain AS, et al. Molecular properties of WHO essential drugs and provisional biopharmaceutical classification. Mol Pharm 2004;1:85-96.

18. Food and Drug Administration. Guidance for Industry: Waiver of in vivo bioavailability and bioequivalence studies for immediate-release solid oral dosage forms based on a Biopharmaceutics Classification System; 2017. Available from: 
https://www.fda.gov/media/70963/download. [Last accessed on $01 \mathrm{Feb} 2021]$.

19. United States Pharmacopeia and National Formulary USP43NF38; The United States Pharmacopeial Convention, Inc: Rockville MD; 2020.

20. Martín MJ, Pablos F, González AG. Simultaneous determination of caffeine and non-steroidal anti-inflammatory drugs in pharmaceutical formulations and blood plasma by reverse-phase HPLC from linear gradient elution. Talanta 1999;49:453-9.

21. Muchlisyam AYS, Sinaga SM. Application and validation of derivative spectrophotometric for determination levels of ternary mixtures of paracetamol, propyphenazone, and caffeine in tablet dosage form. Asian J Pharm Clin Res 2018;11:8-11.

22. Khoshayand MR, Abdollahi H, Shariatpanahi M, Saadatfard S, Mohammadi A. Simultaneous spectrophotometric determination of paracetamol, ibuprofen and caffeine in pharmaceuticals by chemometric methods. Spectrochim Acta A 2008;70:491-9.

23. Dang HV, Thi Thu HT, Thi Ha LD, Mai HN. RP-HPLC and UV spectrophotometric analysis of paracetamol, ibuprofen, and caffeine in solid pharmaceutical dosage forms by derivative, fourier, and wavelet transforms: a comparison study. J Anal Methods Chem 2020. DOI:10.1155/2020/8107571.

24. Serrano N, Castilla O, Arino C, Diaz Cruz MS, Diaz Cruz JM. Commercial screen-printed electrodes based on carbon nanomaterials for a fast and cost-effective voltametric determination of paracetamol, ibuprofen and caffeine in water samples. Sensors 2019;19:4039.

25. Zambakjian C, Sakur AA. A new gas chromatographic method development and validation for the simultaneous determination of ibuprofen and caffeine in bulk and pharmaceutical dosage form. Future J Pharm Sci 2020;6:110.

26. Lemos de Souza M, Otero JC, Lopez Tocon I. Comparative performance of citrate, borohydride, hydroxylamine and $\beta$ cyclodextrin silver sols for detecting ibuprofen and caffeine pollutants by means of surface-enhanced Raman spectroscopy. Nanomaterials 2020;10:2339.

27. Mohammadnejad M. Simultaneous determination of ibuprofen and caffeine in urine samples by combining MCR-ALS and excitation-emission data. Anal Bioanal Chem Res 2016;3:123-30.
28. Lofty HM, Saleh SS. Recent development in ultraviolet spectrophotometry through the last decade (2006-2016): a review. Int J Pharm Pharm Sci 2016;8:40-56.

29. Podczeck F. Comparison of in vitro dissolution profiles by calculating mean dissolution time (MDT) or mean residence time (MRT). Int J Pharm 1993;97:93-100.

30. Anderson NH, Bauer M, Boussac N, Khan Malek R, Munden P, Sardaro M. An evaluation of fit factors and dissolution efficiency for the comparison of in vitro dissolution profiles. J Pharm Biomed Anal 1998;17:811-22.

31. Cardot JM, Beyssac E, Alrici M. In vitro-in vivo correlation: importance of dissolution in IVIVC. Dissolut Technol 2007;14:15-9.

32. Yuksel N, Kanik AE, Baykara $\mathrm{T}$. Comparison of in vitro dissolution profiles by ANOVA-based, model-dependent andindependent methods. Int J Pharm 2000;209:57-67.

33. Zhang Y, Huo M, Zhou J, Zou A, Li W, Yao C, Xie S. DDSolver: an add-in program for modeling and comparison of drug dissolution profiles. AAPS J 2010;12:263-71.

34. Ilango KB, Kavimani S. A systematic review of mathematical models of pharmaceutical dosage forms. Int J Curr Pharm Rev Res 2015;6:59-70.

35. Langenbucher $F$. Linearization of dissolution rate curves by the Weibull distribution. J Pharm Pharmacol 1972;24:979-81.

36. Medina JR, Cortes M, Romo E. Comparison of the USP Apparatus 2 and 4 for testing the in vitro release performance of ibuprofen generic suspensions. Int J Appl Pharm 2017;9:90-5.

37. Medina R, Cazares IS, Hurtado M, Domínguez Ramirez AM. Estimation of acetaminophen and ibuprofen in tablets by a derivative UV method: characterization of in vitro release using USP apparatuses 2 and 4. Lat Am J Pharm 2017;36:706-15.

38. Liu X, Liu S, Wu J, Fang Z. Simultaneous monitoring of aspirin, phenacetin and caffeine in compound aspirin tablets using a sequential injection drug-dissolution testing system with partial least squares calibration. Anal Chim Acta 1999;392:273-81.

39. Franek F, Holm P, Larsen F, Steffansen B. Interaction between fed gastric media (Ensure Plus ${ }^{\circledR}$ ) and different hypromellose based caffeine controlled release tablets: comparison and mechanistic study of caffeine release in fed and fasted media versus water using the USP dissolution apparatus 3 . Int J Pharm 2014;461:419-26. 